\title{
Surveillance Colonoscopy After a Resection of Colorectal Cancer
}

\author{
Byung Chun Kim \\ Department of Surgery, Hallym University Kangnam Sacred Heart Hospital, Hallym University College of Medicine, Seoul, Korea
}

\section{See Article on Page 182-186}

Postoperative surveillance colonoscopy is regarded as an effective tool for the detection and the diagnoses of metachronous cancer and adenomas. Detection and removal of adenomatous polyps though postoperative colonoscopy may reduce the risk of recurrence of colon cancer and advanced adenomas [1]. National Comprehensive Cancer Network guidelines recommend postoperative surveillance colonoscopy within the first year after a resection of colorectal cancer [2]. Postpolypectomy surveillance guidelines published by the US Multi-society Task Force on Colorectal Cancer and based on the number of polyps, the polyp size, and the pathology were presented in 2006. In 2012, those guidelines added surveillance recommendations for serrated lesions to the previous guidelines. Guidelines are to delineate predictors of advanced pathology, both cancer and advanced adenomas. According to the guidelines, patients can be more definitely stratified at their baseline colonoscopies into those at lower risk and those at increased risk for advanced neoplasia [3]. Guidelines for postoperative surveillance colonoscopy recommend that the presence of adenomas and sessile serrated polyps be considered to determine the follow-up interval [3]. Also recommended is that the surveillance interval be based on the risk of polyps found at index colonoscopy [3]. Ratuapli et al. [4] said that knowledge of the pathology of the actual polyp does not change the postpolypectomy surveillance recommendations. Interval cancers within one year after surgery may also represent lesions that were missed on the index colonoscopy. The experienced endoscopist will miss about

Correspondence to: Byung Chun Kim, M.D.

Department of Surgery, Hallym University Kangnam Sacred Heart Hospital, Hallym University College of Medicine, 1 Singil-ro, Yeongdeungpo-gu, Seoul 07441 , Korea

Tel: +82-2-829-5130, Fax: +82-2-849-4469

E-mail: bckimgs@hallym.or.kr

(c) 2015 The Korean Society of Coloproctology

This is an open-access article distributed under the terms of the Creative Commons Attribution NonCommercial License (http://creativecommons.org/licenses/by-nc/3.0) which permits unrestricted noncommercial use, distribution, and reproduction in any medium, provided the original work is properly cited.
$15 \%$ of neoplastic polyps smaller than $10 \mathrm{~mm}$ in size, but will rarely miss larger polyps [5].

Another study showed an overall miss rate for adenomas of $24 \%$; only $6 \%$ of adenomas with sizes larger than $1 \mathrm{~cm}$ were overlooked during the first examination [6]. Brenner et al. [7] demonstrated that the protective effect of colonoscopy against colorectal cancer was not uniform throughout the colon and that the right colon had a lower rate of protection. Factors that may contribute to lower adenoma detection, particularly in the right colon, include the prevalence of flat and depressed lesions, as well as serrated adenomas, in the more proximal segments, which are more difficult to visualize [7]. A higher proportion of polyps were adenomatous in the right and the proximal colon compared with the distal colon [8]. The adenoma detection rates for the proximal colon (22.9\%) and the right colon (17.1\%) were significantly higher than the adenoma detection rate for the left colon (13.5\%) (both $\mathrm{P}<0.001$ ) [8]. A considerable variation in adenoma detection exists among endoscopists. Colonoscopies performed by endoscopists with higher adenoma detection rates are associated with lower rates of interval cancer [8].

In this study, the authors said that in the 116 enrolled patients, the incidence of total polyps during postoperative surveillance colonoscopy was $53.4 \%$ and that the incidence of neoplastic polyps was $25.9 \%$. They also said that the miss rate of total polyps was $37.4 \%$ and the miss rate of neoplastic polyps was $24.2 \%$ during postoperative colonoscopy. The missed neoplastic polyps were located in the right colon and the proximal part from the primary tumor at a higher percentage. When more neoplastic polyps were detected during preoperative colonoscopy, more neoplastic polyps were missed during postoperative colonoscopy [9].

Repeat surveillance colonoscopy earlier than recommended may increase healthcare expenditures, and delayed surveillance colonoscopy may increase the number of patients with an interval cancer [4]. Baseline postoperative surveillance colonoscopy with excellent patient preparation and adequate withdrawal time could reduce the miss rate for colorectal cancer and adenomas. Postoperative surveillance colonoscopy is very important because it can have a great effect on reducing the incidence of colorectal cancer in patients with adenomatous polyps. Especially, the right side of 
the colon should be thoroughly examined at the time of postoperative surveillance colonoscopy.

\section{CONFLICT OF INTEREST}

No potential conflict of interest relevant to this article was reported.

\section{REFERENCES}

1. Bertario L, Russo A, Sala P, Pizzetti P, Ballardini G, Andreola S, et al. Predictors of metachronous colorectal neoplasms in sporadic adenoma patients. Int J Cancer 2003;105:82-7.

2. National Comprehensive Cancer Network. NCCN guidelines for patients [Internet]. Fort Wathington (PA): National Comprehensive Cancer Network; c2015 [cited 2015 Jun 10]. Available from: http://www.nccn.org/patients/guidelines/default.aspx.

3. Winawer SJ, Zauber AG, Fletcher RH, Stillman JS, O’brien MJ, Levin B, et al. Guidelines for colonoscopy surveillance after polypectomy: a consensus update by the US Multi-Society Task Force on Colorectal Cancer and the American Cancer Society. CA Can- cer J Clin 2006;56:143-59.

4. Ratuapli SK, Gurudu SR, Atia MA, Crowell MD, Umar SB, Harrison ME, et al. Postcolonoscopy followup recommendations: comparison with and without use of polyp pathology. Diagn Ther Endosc 2014;2014:683491.

5. Hixson LJ, Fennerty MB, Sampliner RE, McGee D, Garewal H. Prospective study of the frequency and size distribution of polyps missed by colonoscopy. J Natl Cancer Inst 1990;82:1769-72.

6. Rex DK, Cutler CS, Lemmel GT, Rahmani EY, Clark DW, Helper DJ, et al. Colonoscopic miss rates of adenomas determined by back-to-back colonoscopies. Gastroenterology 1997;112:24-8.

7. Brenner H, Hoffmeister M, Arndt V, Stegmaier C, Altenhofen L, Haug U. Protection from right- and left-sided colorectal neoplasms after colonoscopy: population-based study. J Natl Cancer Inst 2010;102:89-95.

8. Boroff ES, Gurudu SR, Hentz JG, Leighton JA, Ramirez FC. Polyp and adenoma detection rates in the proximal and distal colon. Am J Gastroenterol 2013;108:993-9.

9. Paik JH, Jung EJ, Ryu CG, Hwang DY. Detection of polyps after resection of colorectal cancer. Ann Coloproctol 2015;31:182-6. 